\title{
The relationship between mean platelet volume and brucellosis
}

\section{Ortalama trombosit hacmi ile bruselloz arasındaki ilişki}

Ercan Varol*

Department of Cardiology (Prof. E. Varol, MD), Süleyman Demirel University School of Medicine, TR-32150 Isparta

Geliş tarihi/Received: July 02, 2014; Kabul tarihi/Accepted: October 27, 2014

\section{*Corresponding author:}

Dr. Ercan Varol, Kardiyoloji Anabilim Dalı, Süleyman Demirel Ünivesitesi Tıp Fakültesi, TR32150 Isparta. E-mail: drercanvarol@yahoo.com

\section{Dear Editor,}

I read the article published by Kader et al. [1] with a great interest. They assessed the mean platelet volume (MPV) values in patients with brucellosis. MPV values were significantly lower in the pretreatment group in brucellosis patients. I congratulate the authors for their contribution of the present study, which is successfully written. On the other hand, I want to make minor criticism about this study from methodological aspect. They screened complete blood counts and serum tube agglutination test results retrospectively. However, they didn't mention about MPV measurement technique in detail which is very important.

Accurate measurements of platelet count and volume are important for diagnostic, therapeutic, and research purposes. The choice of anticoagulant (ethylenediaminetetraacetic acid (EDTA) or citrate), time interval of measurement, and temperature at which MPV is analyzed are important factors in MPV measurement. The time dependent swelling of platelets in samples anticoagulated with EDTA can result in an artefactual increase of MPV and misinterpretation of prothrombotic changes [2]. In actual daily practice, MPV measurements are performed at room temperature and temperature factor can be neglibible. However, the choice of anticoagulant and time interval of MPV measurement are important issue. MPV increases over time in EDTAanticoagulated samples and this increase was shown to be proportional with the delay in time between sample collection and laboratory analysis. With impedance counting, the MPV increases over time as platelets swell in EDTA, with increases of $7.9 \%$ within 30 min having been reported and an overall increase of $13.4 \%$ over $24 \mathrm{~h}$, although the majority of this increase occurs within the first $6 \mathrm{~h}$ [2]. Dastjerdi et al. [3] recommended to measure MPV within 1 hour regardless of anticoagulant. Lancé et al. [3] reported that an optimal stability was detected in K2-EDTA after 120 minutes. It is widely accepted that platelet swelling in test tubes can be minimized by rapid processing of samples (within less than $1 \mathrm{~h}$ ). For reliable MPV measurement, the potential influence of EDTA anticoagulant on the MPV must be carefully controlled by standardizing the time delay between sampling and analysis.

Secondly, there are significant associations of MPV with many cardiovascular risk factors like smoking, obesity, hypertension, diabetes mellitus, prediabetes, hyperlipidemia, metabolic syndrome, atrial fibrillation and fatty liver disease [4]. They didn't mention about the body mass index, metabolic syndrome, rhythm status and fatty liver disease in patients and controls. It has been shown that obesity, metabolic syndrome, atrial 
fibrillation and fatty liver disease increase MPV values [4]. Absolutely, these factors should be considered in MPV assessment. Moreover, they excluded patients with arterial stiffness. Did they look at the arterial stiffness parameters and which technique did they use? It would have been useful if the authors had clarified this situation also.

MPV is universally available with routine blood counts by automated hemograms. However, MPV can be affected by man cardiovascular risk factors. Because of that all confounding factors should be to taken into account. In addition, standardized methods must be used in MPV measurement.

\section{References}

1. Kader C, Yolcu S, Erbay A. Evaluation of mean platelet volume levels in brucellosis patients. Cumhuriyet Medical Journal (CMJ) 2013; 35: 488-94.

2. Lancé MD, Sloep M, Henskens YM, Marcus MA. Mean platelet volume as a diagnostic marker for cardiovascular disease: Drawbacks of preanalytical conditions and measuring techniques. Clin Appl Thromb Hemost 2012; 18: 5618.

3. Dastjerdi MS, Emami T, Najafian A, Amini M. Mean platelet volume measurement, EDTA or citrate? Hematology 2006; 11: 317-9.

4. Vizioli L, Muscari S, Muscari A. The relationship of mean platelet volume with the risk and prognosis of cardiovascular diseases. Int J Clin Pract 2009; 63: 150915.

5. Gasparyan AY, Ayvazyan L, Mikhailidis DP, Kitas GD. Mean platelet volume 2011. 